\title{
Ten cities cross-sectional questionnaire survey of children asthma and other allergies in China
}

\author{
ZHANG YinPing $^{1^{*}}$, LI BaiZhan ${ }^{2 *}$, HUANG Chen ${ }^{3}$, YANG Xu ${ }^{4}$, QIAN Hua ${ }^{5}$, DENG QiHong ${ }^{6}$, \\ ZHAO ZhuoHui ${ }^{7}$, LI AnGui ${ }^{8}$, ZHAO JiaNing ${ }^{9}$, ZHANG Xin ${ }^{10}$, QU Fang ${ }^{1}$, HU Y ${ }^{3}$, YANG Qin ${ }^{2}$, \\ WANG Juan ${ }^{2}$, ZHANG Ming ${ }^{4}$, WANG Fang ${ }^{9}$, ZHENG XiaoHong ${ }^{5}$, LU Chan ${ }^{6}$, LIU ZhiJian ${ }^{8}$, \\ SUN YueXia ${ }^{11}$, MO JinHan $^{1}$, ZHAO YiLi $^{5}$, LIU Wei ${ }^{3}$, WANG TingTing ${ }^{12}$, NORBÄCK Dan ${ }^{13}$, \\ BORNEHAG Carl-Gustaf ${ }^{14} \&$ SUNDELL Jan ${ }^{1 *}$
}

${ }^{1}$ Department of Building Science, Tsinghua University, Beijing 100084, China;

${ }^{2}$ Key Laboratory of Three Gorges Reservoir Region's Eco-Environment, Chongqing University, Chongqing 400030, China;

${ }^{3}$ School of Environment and Architecture, University of Shanghai for Science and Technology, Shanghai 200093, China;

${ }^{4}$ College of Life Sciences, Central China Normal University, Wuhan 430079, China;

${ }^{5}$ School of Energy \& Environment, Southeast University, Nanjing 210096, China;

${ }^{6}$ School of Energy Science and Engineering, Central South University, Changsha 410083, China;

${ }^{7}$ School of Public Health, Fudan University, Shanghai 200032, China;

${ }^{8}$ School of Environmental and Municipal Engineering, Xi'an University of Architecture and Technology, Xi'an 710055, China;

${ }^{9}$ School of Municipal and Environmental Engineering, Harbin Institute of Technology, Harbin 150090, China;

${ }^{10}$ Research Center for Environmental Science and Engineering, Shanxi University, Taiyuan 030006, China;

${ }^{11}$ School of Environmental Science and Engineering, Tianjin University, Tianjin 300072, China;

${ }^{12}$ School of Public Health, Xinjiang Medical University, Urumqi 830011, China;

${ }^{13}$ Department of Occupational and Environmental Medicine, University Hospital and Uppsala University, Uppsala SE-751, Sweden;

${ }^{14}$ Public Health Sciences, Karlstad University, SP Technical Research Institute of Sweden, Uppsala SE-751, Sweden

Received February 20, 2013; accepted May 15, 2013; published online May 29, 2013

\begin{abstract}
Asthma, rhinitis and eczema (allergic or non-allergic) have increased throughout the world during the last decades, especially among children. Changes in the indoor environment are suspected to be important causes. China has experienced a dramatic change in indoor environmental exposures during the past two decades. However, such changes and their associations with children's asthma and other health aspects have not been thoroughly studied. China, Children, Homes, Health (CCHH), Phase I, was a cross-sectional questionnaire survey of 48219 children 1-8 years old in 10 Chinese cities during 2010-2012. The questionnaire includes the International Study of Asthma and Allergies in Childhood (ISAAC) core health questions and additional questions regarding housing, life habits and outdoor environment. In health analyses, children aged 3-6 years old were included. The prevalences of doctor diagnosed asthma varied from $1.7 \%$ to $9.8 \%$ (mean 6.8\%), a large increase from $0.91 \%$ in 1999 and $1.50 \%$ in 2000. The prevalence of wheeze, rhinitis and atopic eczema (last 12 months) varied from $13.9 \%$ to $23.7 \%, 24.0 \%$ to $50.8 \%$ and $4.8 \%$ to $15.8 \%$, respectively. Taiyuan had the lowest prevalences of all illnesses and Shanghai the highest, except for wheezewhere the highest value was for Urumqi. We found (1) no obvious association between disease prevalences and ambient $\mathrm{PM}_{10}$ concentrations and (2) higher prevalences of disease in humid climates with hot summers and cold winters, but with no centrally heated buildings. Associations between the diseases and economic status as indexed by Gross Domestic Product (GDP) requires further study.
\end{abstract}

environmental health, indoor air quality, homes, exposure, urbanization

Citation: Zhang Y P, Li B Z, Huang C, et al. Ten cities cross-sectional questionnaire survey of children asthma and other allergies in China. Chin Sci Bull, 2013, 58: 4182-4189, doi: 10.1007/s11434-013-5914-Z

*Corresponding authors (email: sundellcc@gmail.com; zhangyp@tsinghua.edu.cn; baizhanli@cqu.edu.cn) 
Asthma prevalence has increased worldwide during the last decades [1-7]. The magnitude of increase has generally been smaller in low-income countries, but the rates of increase may be accelerating $[1,4,5]$. The International Study of Asthma and Allergies in Childhood (ISAAC) reported that the highest prevalences of asthma in children aged 6-7 years were in the UK, Australia, New Zealand and Ireland, while the lowest prevalences were in Indonesia, Albania, Romania, Georgia and Greece [1]. In many parts of the world, a large fraction of children have or have had asthma, wheeze, rhinitis or eczema $[1,2]$. The cost, family burden and impaired life quality due to asthma and allergies are severe public health problems. It is anticipated that there will be about 300 million people suffering from asthma by 2025 [6].

Neither genetic factors [7], outdoor environmental pollution [8-12], racial factors [13], nor socio-economic status [14] can wholly explain this dramatic increase. People spend a large part of their time indoors and pre-school children spend a longer time in homes compared with adults $[15,16]$. The indoor environment, especially in homes, has been implicated as having an important role in inducing and/or exacerbating asthma and allergies among children [17-25].

The ISAAC project was started in 1990 in Germany and New Zealand with the aim of quantifying the prevalence and characterizing the severity of asthma and allergies worldwide [26]. Studies had been conducted in 236 centers in 98 countries [27] before 2009. However, ISAAC studies lack data on indoor environmental and building related risk factors. The idea to study "asthma and the home environment" was initiated in Sweden because of the Allergy Inquiry (a 1987-1989 governmental inquiry) to identify causes of the dramatic increase of allergic children in Sweden. The Swedish study, "Dampness in Buildings and Health" (DBH) was started in 2000 with the aim of characterizing associations between building dampness and asthma and allergies among children. Its hypothesis and background were based on scientific state-of-the-art reviews [17,28-33]. Questionnaires and experimental protocols were designed for a multidisciplinary study involving environmental science, engineering, chemistry and microbiology in addition to medicine and public health. By 2010, studies built on the platform of the Swedish study had been carried out in several countries [19,22,34-38].

The prevalences of asthma and allergies have, in some western countries, recently stabilized or even decreased $[39,40]$. These changing trends coincide with the currently slower rate of change in indoor environment exposures in these countries. China, a developing country, is experiencing rapid and dramatic changes in indoor environment exposures due to its rapid modernization and urbanization. National surveys of asthma in Chinese children aged 0-14 years in 1990 and 2000 by the Childhood Asthma Collabo- rative Group of China [41] as well as a number of other studies indicate that asthma and allergies have increased in China [4,7,42-51]. However, information about indoor exposure has been included to only a small extent and in only a few studies [52,53].

In September 2010, we launched the project China, Children, Homes, Health $(\mathrm{CCHH})$ in 10 major cities in China. Ten universities are involved in $\mathrm{CCHH}$. There are two phases: Phase I is a cross-sectional questionnaire study of the prevalence of children's asthma, allergies and airway infections, and home environmental exposures (2010.112012.4) (See Table S1); Phase II will be a case-control study with measurements of pollutants in sampled air, dust and urine (2012.11-). The objectives of the CCHH research project are:

(1) to investigate the prevalences of asthma, allergies and airway infections in major Chinese cities with different climates, outdoor air quality, and economic level;

(2) to investigate and compare indoor environmental aspects of sick and healthy children's homes;

(3) to compare risk and protective factors in different cities of China;

(4) to compare findings from $\mathrm{CCHH}$ with those of other countries and regions outside of mainland China;

(5) to provide epidemiological data as a foundation for the prevention of asthma and allergies among children in China.

This paper reports some basic data from all cities as well as some historic trends in the prevalences of asthma, allergies and the percentage of children who have had one or more episodes of pneumonia.

\section{Subjects and methods}

\subsection{Sites studied and children selected}

The CCHH study was carried out in 10 cities in different geographic regions of China with different per capita economic statuses and outdoor environmental pollution levels (Table 1 and Figure 1). Every city included urban areas. Some cities included rural or suburban areas. Kindergartens or daycare centers or primary schools were randomly selected in each city.

\subsection{Questionnaire design and pilot study}

$\mathrm{CCHH}$ research used questions from the ISAAC study [56] about children's asthma, and allergies. Questions from the Swedish DBH study about the home environments [19] were adapted so as to be relevant to Chinese home characteristics [57]. The questionnaire was tested in a pilot study of 100 children in Chongqing in April 2010, and thereafter adjusted to improve readability. For details about questionnaire design, see articles for specific CCHH cities [58-68]. 
Table 1 Economic status, geography, climate and $\mathrm{PM}_{10}$ concentration of the investigated cities in CCHH studies

\begin{tabular}{|c|c|c|c|c|c|}
\hline \multirow{2}{*}{$\begin{array}{l}\text { Cities } \\
\text { (from north to south) }\end{array}$} & \multirow{2}{*}{$\begin{array}{c}\text { Economic status } \\
(\text { Income, per capita GDP, kRMB) })^{\mathrm{a}}\end{array}$} & \multirow{2}{*}{ Dry/humid [54] } & \multirow{2}{*}{ Type of climate [55] } & \multicolumn{2}{|c|}{$\begin{array}{l}\text { Annual mean concentration } \\
\text { of } \mathrm{PM}_{10}\left(\mu \mathrm{g} / \mathrm{m}^{3}\right)^{\mathrm{b})}\end{array}$} \\
\hline & & & & 2001 & 2010 \\
\hline Harbin & 37.0 & Sub-humid & Severe cold & 134.7 & 102.6 \\
\hline Urumqi & 44.9 & Dry & Severe cold & 203.6 & 139.1 \\
\hline Beijing & 75.9 & Sub-humid & Cold & 175.2 & 122.3 \\
\hline Taiyuan & 44.3 & Sub-humid & Cold & 203.7 & 89.2 \\
\hline Xi'an & 38.3 & Sub-humid & Cold & 156.5 & 126.1 \\
\hline Nanjing & 63.7 & Humid & Hot summer and cold winter & 140.0 & 112.7 \\
\hline Shanghai & 76.1 & Humid & Hot summer and cold winter & 101.7 & 79.3 \\
\hline Wuhan & 59.0 & Humid & Hot summer and cold winter & 150.4 & 107.0 \\
\hline Chongqing & 27.6 & Humid & Hot summer and cold winter & 141.5 & 102.5 \\
\hline Changsha & 66.4 & Humid & Hot summer and cold winter & 181.0 & 83.6 \\
\hline
\end{tabular}

a) From the annual report of each city, using 2010 data (except Taiyuan, 2009); b)from the Ministry of Environmental Protection of China.

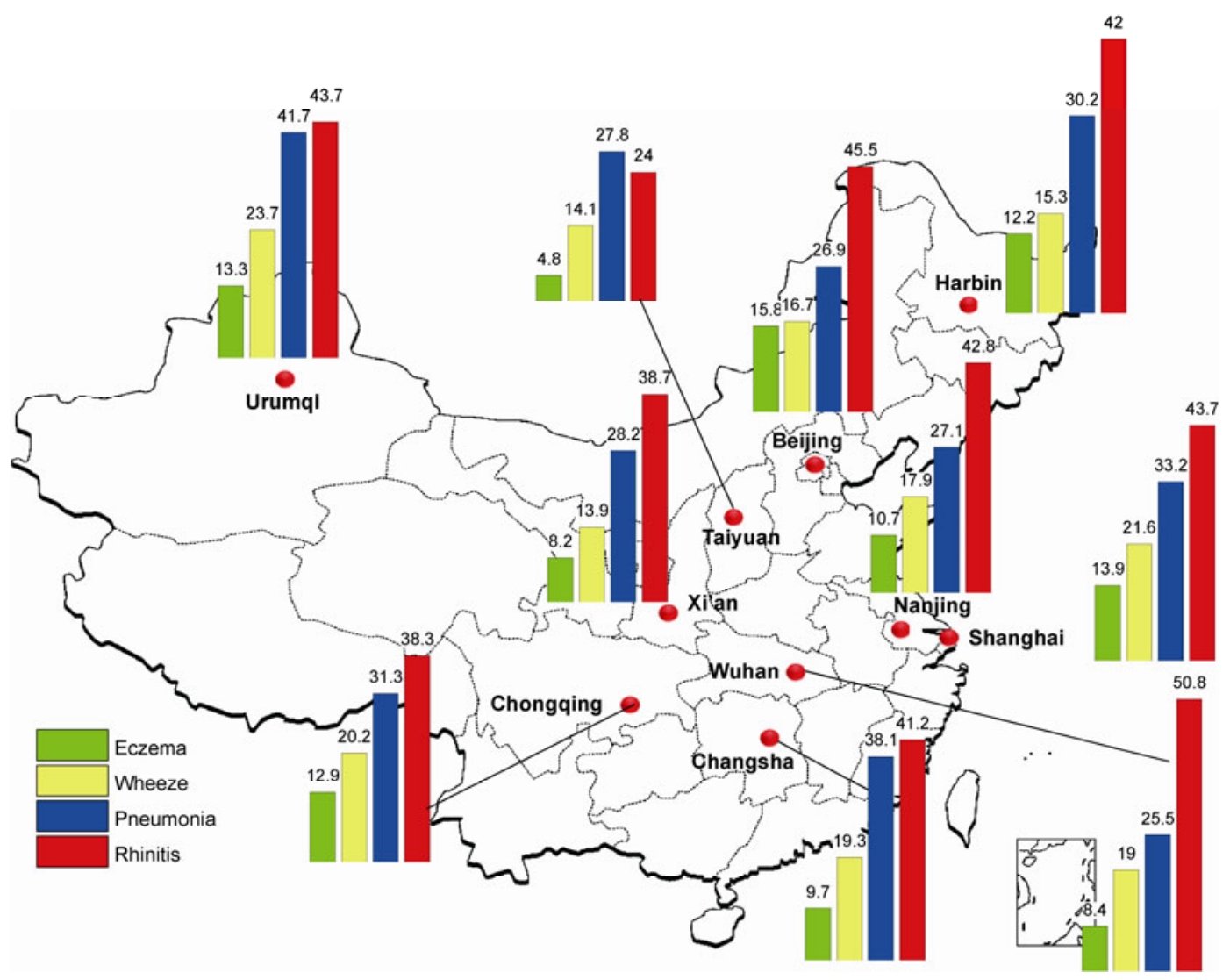

Figure 1 Prevalences (\%) of rhinitis, wheeze, and atopic eczema in the last 12 months and pneumonia (at least one episode), for children 3-6 years old in all cities except Taiyuan (3-5) and Wuhan (5-6) years old.

\subsection{Procedure for Phase I study}

The procedure for the questionnaire survey was as follows: We first contacted the director of each kindergarten. After he or she agreed on participation, questionnaires were distributed by the responsible teachers in each class to the children's parents or legal guardians. Finally, parents returned the questionnaires to the teachers, and we collected the completed questionnaires from the teachers.

The data were input and statistically analyzed by SPSS software.

\section{Results}

In the $\mathrm{CCHH}$ investigation Phase I, parents of 48219 children aged 1-8 responded to the questionnaire, yielding a $76.9 \%$ average response rate. Table 2 presents detailed information on children's ages, numbers of respondents, and response rates. Non-respondents were tracked by short questionnaires in Chongqing. A sample of 300 children was randomly selected from those who had not responded in the cross-sectional study, and 206 responded. The five 
Table 2 Number of respondents and response rates in investigated cities

\begin{tabular}{lccc}
\hline \multicolumn{1}{c}{ Cities } & $\begin{array}{c}\text { Age } \\
\text { (years) }\end{array}$ & $\begin{array}{c}\text { Number of } \\
\text { respondents }\end{array}$ & $\begin{array}{c}\text { Response } \\
\text { rate }(\%)\end{array}$ \\
\hline Harbin & $2-8$ & 2506 & 64.1 \\
Urumqi & $2-7$ & 4618 & 81.7 \\
Beijing & $1-8$ & 5876 & 65.0 \\
Shanghai & $1-8$ & 15266 & 85.3 \\
Nanjing & $1-8$ & 4014 & 65.7 \\
Xi'an & $1-8$ & 2020 & 83.5 \\
Taiyuan & $1-6$ & 3700 & 82.2 \\
Wuhan & $1-8$ & 2193 & 91.4 \\
Changsha & $1-8$ & 2727 & 59.0 \\
Chongqing & $1-8$ & 5299 & 74.5 \\
\hline
\end{tabular}

questions in the short questionnaires asked about home site (location), gender, wheezing in the last 12 months, visible damp stains and family smoking. There were no significant differences between responses to the short questionnaire, and responses to the same questions in the long questionnaire (see Table S2).

Distributions of gender, age and family allergic histories among investigated children in 10 cities are shown in Table
3. As the number of children in age groups $1,2,7$ and 8 were small in most cities, further analyses of health outcomes were for children 3-6 years of age, except for Taiyuan (3-5 years of age) and Wuhan (5-6 years of age). Table 4 shows the age-adjusted prevalences of illnesses (3-6 years, except Taiyuan (3-5) and Wuhan (5-6)). Prevalences for the last 12 months of wheeze, rhinitis, and eczema, as well as the percentages of children who had had one or more lifetime episodes of pneumonia, are shown in Figure 1.

Asthma was determined as a "yes" reply to the question "Has your child ever been diagnosed with asthma by a doctor?". In Figure 2, the findings of the CCHH ten city study in 2010-2011 are compared with mean prevalences among 0-14 year old children in 1990 and 2000 [41]. All prevalences are normalized against 1990 data. Figure 3 shows the same comparison but with actual (non-normalized) data. Prevalences of doctor-diagnosed asthma have increased faster during the last ten years than during the decade from 1990 to 2000. Urumqi, Wuhan, Beijing and Shanghai had the most rapid increase in the last decade.

Figures 4 and 5 show ecological comparisons. Southern cities, humid all year but cold in winter and without heating,

Table 3 Percentages by gender, allergy in the family and children's ages in CCHH Phase I cities ${ }^{\text {a) }}$

\begin{tabular}{|c|c|c|c|c|c|c|c|c|c|c|c|}
\hline \multirow{2}{*}{ City name } & \multicolumn{2}{|c|}{ Gender $(\%)$} & \multirow{2}{*}{$\begin{array}{c}\text { Allergy in family (\%) } \\
\text { Yes }\end{array}$} & \multicolumn{8}{|c|}{ Age $(\%)$} \\
\hline & Male & Female & & 1 & 2 & 3 & 4 & 5 & 6 & 7 & 8 \\
\hline Harbin & 50.3 & 49.7 & 13.3 & 0 & 1.8 & 10.3 & 21.2 & 23.0 & 27.3 & 14.4 & 2.0 \\
\hline Urumqi & 53.6 & 46.4 & 19.8 & 0 & 2.1 & 24.3 & 36.0 & 30.4 & 6.9 & 0.1 & 0.0 \\
\hline Shanghai & 50.9 & 49.1 & 19.4 & 0.2 & 0.1 & 5.0 & 37.2 & 29.4 & 22.6 & 5.2 & 0.3 \\
\hline Nanjing & 51.2 & 48.8 & 15.8 & 0.1 & 1.0 & 11.4 & 23.6 & 25.2 & 24.9 & 12.0 & 1.8 \\
\hline Xi'an & 53.3 & 46.7 & 9.2 & 0.1 & 1.4 & 19.7 & 28.1 & 28.6 & 19.7 & 2.2 & 0.2 \\
\hline Wuhan & 52.7 & 47.3 & 16.9 & 0.5 & 0.1 & 1.4 & 3.6 & 4.8 & 10.3 & 32.2 & 47.1 \\
\hline Changsha & 53.3 & 46.7 & 15.4 & 0.2 & 2.8 & 24.5 & 34.2 & 31.2 & 6.6 & 0.4 & 0.1 \\
\hline Chongqing & 51.3 & 48.7 & 11.1 & 0.3 & 2.4 & 20.0 & 32.4 & 29.6 & 14.1 & 1.1 & 0.1 \\
\hline
\end{tabular}

a) Age 1 means age $\leqslant 1$, age 2 means age $>1$ and $\leqslant 2$, and so on.

Table 4 Age adjusted prevalences of symptoms and illnesses in children 3-6 years old

\begin{tabular}{|c|c|c|c|c|c|c|c|c|c|c|}
\hline & Harbin & Urumqi & Beijing & Shanghai & Nanjing & Xi'an & Taiyuan $^{\mathrm{e})}$ & Wuhan $^{\text {f) }}$ & Changsha & Chongqing \\
\hline Wheeze ever & 19.6 & 35.3 & 22.3 & 27.9 & 23.4 & 20.2 & 21.7 & 31.2 & 27.0 & 26.7 \\
\hline Wheeze last 12 months & 15.3 & 23.7 & 16.7 & 21.6 & 17.9 & 13.9 & 14.1 & 19.0 & 19.3 & 20.2 \\
\hline Dry cough last 12 months & 11.7 & 11.9 & 19.4 & 19.7 & 18.5 & 15.0 & 7.9 & 18.4 & 16.0 & 18.4 \\
\hline Rhinitis ever & 55.3 & 48.9 & 57.7 & 55.2 & 54.6 & 56.5 & 38.6 & 58.7 & 54.2 & 51.6 \\
\hline Rhinitis last 12 months & 42.0 & 43.7 & 45.5 & 43.7 & 42.8 & 38.7 & 24.0 & 50.8 & 41.2 & 38.3 \\
\hline Rhinitis on pet exposure & 1.0 & 4.3 & 3.3 & 4.6 & 2.0 & 2.1 & 2.5 & 9.3 & 2.0 & 2.7 \\
\hline Doctor diagnosed Rhinitis & 2.2 & 9.8 & 7.9 & 11.6 & 8.8 & 3.7 & 2.7 & 23.9 & 8.0 & 6.2 \\
\hline Eczema ever ${ }^{a}$ & 33.1 & 15.3 & 34.7 & 23.4 & 28.4 & 29.0 & 13.6 & 26.0 & 29.9 & 30.4 \\
\hline Eczema last 12 months ${ }^{\text {b) }}$ & 12.2 & 13.3 & 15.8 & 13.9 & 10.7 & 8.2 & 4.8 & 8.4 & 9.7 & 12.9 \\
\hline Croup & 3.2 & 6.3 & 4.3 & 7.6 & 4.2 & 4.5 & 4.0 & 5.8 & 5.9 & 6.3 \\
\hline Pneumonia & 30.2 & 41.7 & 26.9 & 33.2 & 27.1 & 28.2 & 27.8 & 25.5 & 38.1 & 31.3 \\
\hline Common cold $\geqslant 6$ times last 12 months & 6.0 & 7.6 & 9.5 & 8.5 & 9.9 & 7.1 & 4.7 & 6.1 & 7.9 & 18.1 \\
\hline Ear infection ${ }^{\mathrm{c}}$ & 8.3 & 11.9 & 14.9 & 10.5 & 7.8 & 7.7 & 9.0 & 16.2 & 7.7 & 7.8 \\
\hline Food allergy $^{\text {d) }}$ & 22.2 & 16.4 & 23.9 & 19.4 & 20.5 & 12.9 & 12.7 & 17.0 & 17.6 & 16.9 \\
\hline
\end{tabular}

a) Has your child ever had an itchy rash (eczema), which intermittently for at least 6 months? b) In the last 12 months, has your child had itchy skin rash? c) Has your child ever had ear infections? d) Has your child ever developed itchy skin, rash, diarrhea, swollen lips, or swollen eyes as a result of eating the foods below? e) Age adjusted for 3-5 year old children; f) Age adjusted for 5-6 year old children. 


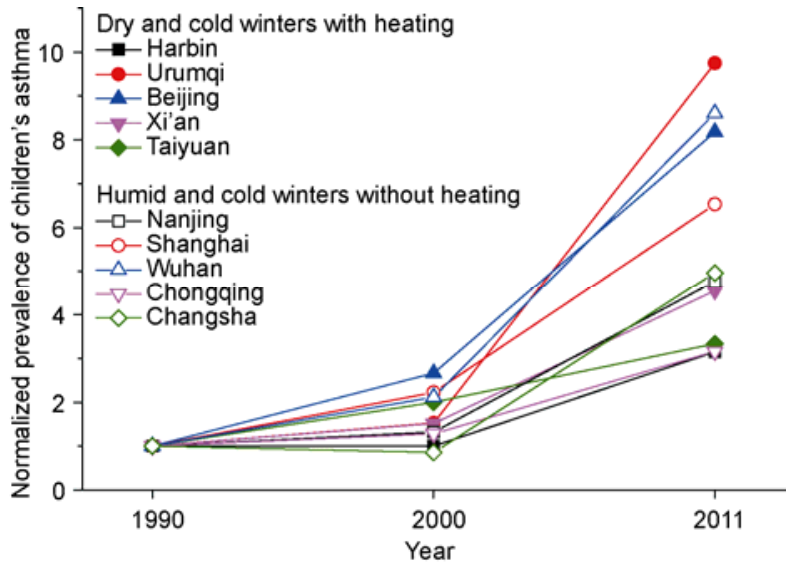

Figure 2 Prevalences of children's asthma normalized for 1990.

had asthma prevalences of $>6.9 \%$. The dry northern cities, which do have heating during winter, had asthma prevalences of $<4 \%$ with the exception of Beijing, with asthma prevalence of $6.3 \%$. There are no associations in ecological analyses between wheeze, rhinitis, eczema and pneumonia; and climate, GDP/capita or ambient $\mathrm{PM}_{10}$. Table 1 also shows that ambient $\mathrm{PM}_{10}$ decreased in all cities during the last 10 years, the years that asthma has increased more rapidly. Figure 5 shows an association between doctor-diagnosed asthma and GDP/capita, which is, however, distorted by the outlier Chongqing.

General characteristics of the study population, housing characteristics, and home dampness and odor reports are given in Tables S3-S5.

\section{Discussion}

The CCHH survey covered 10 major cities in China with different climates, geographies and per capita economic status. In total, there were 48219 children (and homes), of whom 43591 were 3-6 years old, included in the analyses of health outcomes. The mean response rate, $76 \%$, is reasonably high. This study is subject to the limitations inherent in any cross-sectional survey. Data used for analyses were collected retrospectively and relied on parental reports; our findings could therefore be subject to recall bias. A strength of the study is that core ISAAC questions have been validated [69] as have questions on indoor exposures [70, 71]. Non-respondents were reached by a short survey in Chongqing. There were no significant differences in the prevalences of wheezing in the last 12 months between responders and non-responders to the long questionnaire, which indicates that neither selection nor non-response biases are likely present. The possible influence of bias on specific topics is discussed in the articles from each city

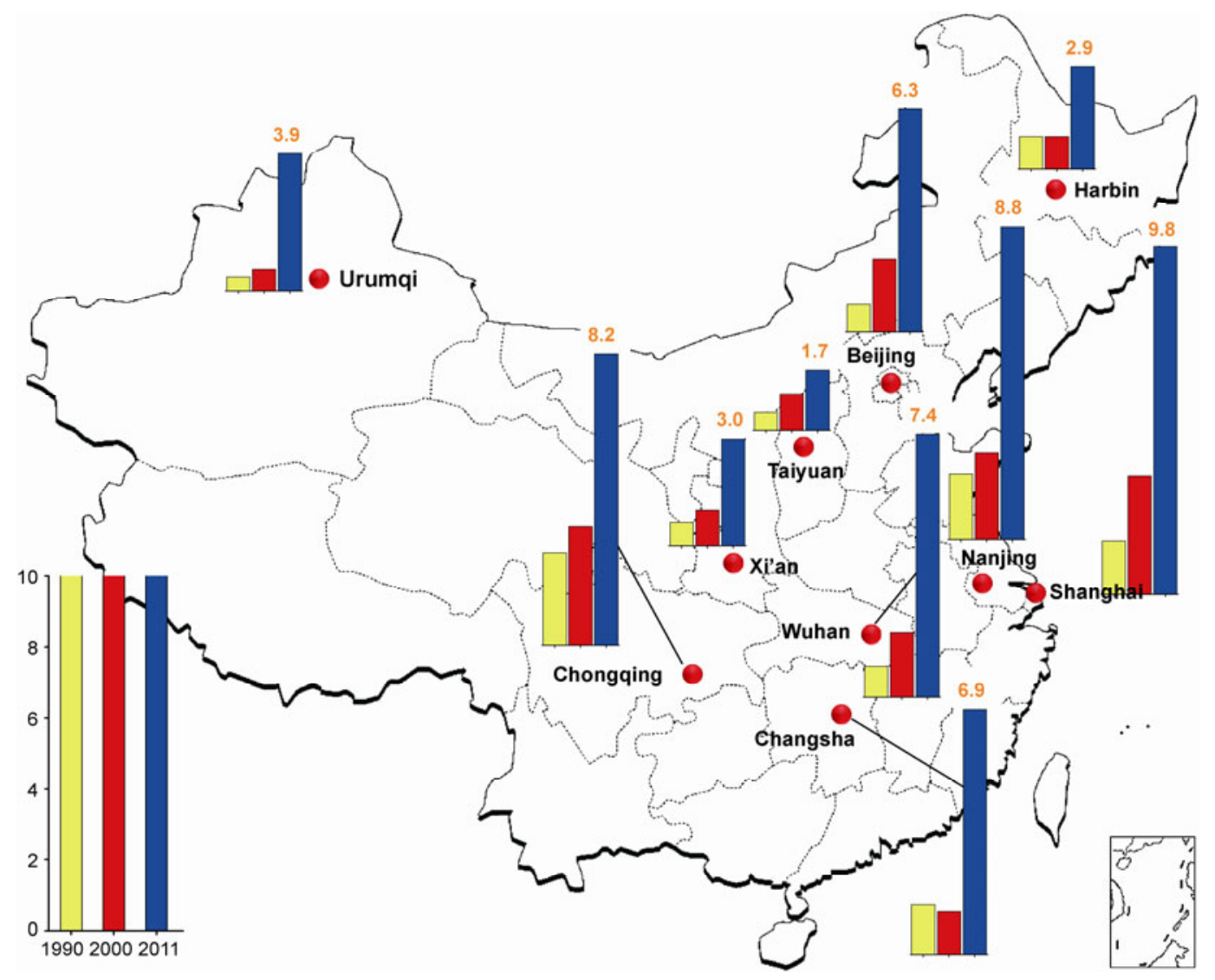

Figure 3 National trends for children's asthma in the cities investigated (3-6 years old, except for Taiyuan (3-5) and Wuhan (5-6) compared with the prevalence for 0-14 years old children 1990, 2000 [41]). 


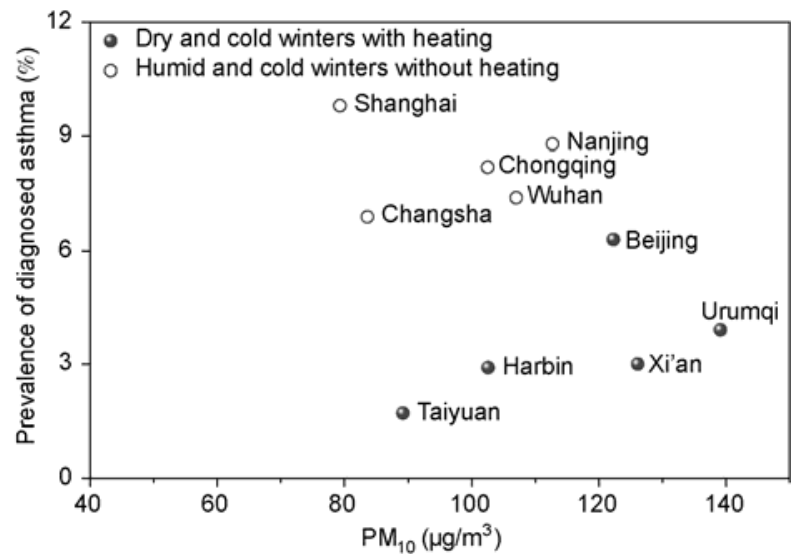

Figure 4 Correlation between outdoor $\mathrm{PM}_{10}$ concentration in 2010 and prevalence of asthma in 2011.

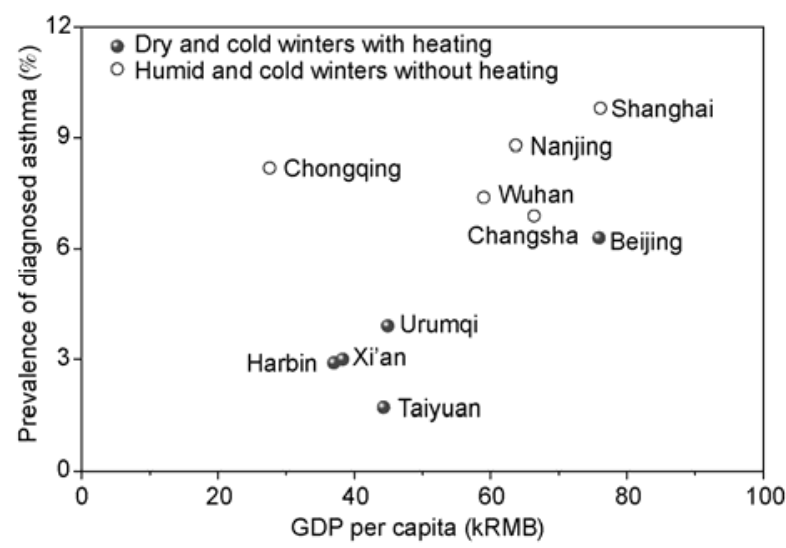

Figure 5 Correlation between GDP per capita in 2010 and prevalence of asthma in 2011.

\section{[58-68].}

The prevalences of doctor-diagnosed asthma in $\mathrm{CCHH}$ cities varied from $1.7 \%$ to $9.8 \%$ (mean $6.8 \%$ ). This represents a great increase from $0.91 \%$ in 1999 ( 287329 children) and $1.50 \%$ in 2000 (299193 children in 27 cities of China). The prevalences of wheeze, rhinitis and eczema (last 12 months) varied from $13.9 \%$ to $23.7 \%, 24 \%$ to $50.8 \%$ and $4.8 \%$ to $15.8 \%$ respectively. For all symptoms, Taiyuan had the lowest prevalences, whereas the more developed eastern cities had the highest prevalences, with the exception of Urumqi, which had the highest prevalence of wheeze. Ecological analyses show no obvious association between diseases and ambient air pollution $\left(\mathrm{PM}_{10}\right)$, or economic status as indexed by GDP (Gross Domestic Product) per capita, but suggest that prevalences were higher in humid climates where summers are hot, winters cold, and there is no heating. In comparison with earlier studies, the prevalences of parentally reported wheeze, rhinitis and eczema, and parentally reported doctor-diagnosed asthma were high, indicating increased prevalences of these symptoms and diseases. Other recent studies $[4,46-51]$ are in agreement with these findings.

The comparisons in Figures 2 and 3 between prevalences of doctor-diagnosed asthma in 1990, 2000 and 2011 are important. However, because our samples of children 1-2 and 7-8 years old were small, the present $\mathrm{CCHH}$ study reports health outcomes for children 3-6 years old. The national studies of 1990 and 2000 [41] surveyed children 0-14 years old, so that a direct comparison is not possible. Nonetheless, the CCHH survey of 10 cities shows that children's asthma has increased. Moreover, the increase has accelerated since 2000 (Figure 2).

The prevalences of wheeze, rhinitis and atopic eczema are not as different between cities as the prevalences of doctor-diagnosed asthma (Figures 1 and 3). The difference in prevalences between parentally reported doctor-diagnosed asthma (Figure 3) and parentally reported symptoms in different regions may be due to regional differences in health care systems. The comparison between Figure 1 (parental reported wheeze) and Figure 3 (parental reported doctor-diagnosed asthma) may partly reflect differences in how likely it is that a child is taken to a clinic for a diagnosis of asthma as well as for rhinitis.

The reported percentage of children who have had at least one doctor-diagnosed episode of pneumonia is high $(25.5 \%-41.7 \%)$, especially given that urban pneumonia rates are generally lower than those of rural areas, where there is extensive exposure to smoke from burning of biomass [72]. The children in this study are primarily living in new and modern apartments with lower air exchange rates than old apartments (see articles from Nanjing [65], and Urumqi [59] for further discussion).

\section{Conclusions}

Prevalences of "allergic" diseases and symptoms have increased in large Chinese cities. More than half of the 3-6 year old children surveyed have had at least one manifestation of wheeze, rhinitis or eczema, and more than one-fourth of children have had at least one episode of pneumonia.

The changes in indoor environmental exposure caused by the modernization of China may in part explain the increasing prevalence of the studied diseases. Certainly, further analyses and research (composition and size effect of PM, e.g.) are necessary to unravel the riddles behind the rapid increases. In Phase II, case-control studies in which pollutants in air, dust and urine are measured, will be done. Nation-wide collaborative research among inter-disciplinary fields and groups will be needed.

This work was supported by the National Natural Science Foundation of China (51136002, 51076079, 51006057), Ministry of Science and Technology of China (2012BAJ02B03) and National High Technology Research and Development Program of China (2010AA064903). The authors are on behalf of CCHH Phase I collaborative group. Sun YueXia and Mo JinHan were the scientific secretaries for the papers. We also thank Zhang JP, Wang $H$ for their contribution in this study, and Louise B. Weschler for careful revisions of the manuscript. 
1 Asher M I, Montefort S, Bjorksten B, et al. Worldwide time trends in the prevalence of symptoms of asthma, allergic rhinoconjunctivitis, and eczema in childhood: ISAAC Phases One and Three repeat multicountry cross-sectional surveys. Lancet, 2006, 368: 733-743

2 Beasley R, Keil U, von Mutius E, et al. Worldwide variation in prevalence of symptoms of asthma, allergic rhinoconjunctivitis, and atopic eczema: ISAAC. Lancet, 1998, 351: 1225-1232

3 Burr M L, Wat D, Evans C, et al. Asthma prevalence in 1973, 1988 and 2003. Thorax, 2006, 61: 296-299

4 Bai J A, Zhao J, Shen K L, et al. Current trends of the prevalence of childhood asthma in three Chinese cities: A multicenter epidemiological Survey. Biomed Environ Sci, 2010, 23: 453-457

5 Lai $\mathrm{C} \mathrm{K} \mathrm{W}$, Beasley R, Crane J, et al. Global variation in the prevalence and severity of asthma symptoms: Phase Three of the International Study of Asthma and Allergies in Childhood (ISAAC). Thorax, 2009, 64: 476-483

6 Masoli M, Fabian D, Holt S, et al. The global burden of asthma: Executive summary of the GINA Dissemination Committee Report. Allergy, 2004, 59: 469-478

7 Wong G W K, Chow C M. Childhood asthma epidemiology: Insights from comparative studies of rural and urban populations. Pediatr Pulmonol, 2008, 43: 107-116

8 D'Amato G, Liccardi G D, Amato M, et al. Respiratory allergic diseases induced by outdoor air pollution in urban areas. Monaldi Arch Chest Dis, 2002, 57: 161-163

9 Anderson H R, Ruggles R, Pandey K D, et al. Ambient particulate pollution and the world-wide prevalence of asthma, rhinoconjunctivitis and eczema in children: Phase One of the International Study of Asthma and Allergies in Childhood (ISAAC). Occup Environ Med, 2010, 67: 293-300

10 McConnell R, Islam T, Shankardass K, et al. Childhood incident asthma and traffic-related air pollution at home and school. Environ Health Perspect, 2010, 118: 1021-1026

11 Chung K A F, Zhang J F, Zhong N S. Outdoor air pollution and respiratory health in Asia. Respirology, 2011, 16: 1023-1026

12 Gruzieva O, Bergstrom A, Hulchiy O, et al. Exposure to air pollution from traffic and childhood asthma until 12 years of age. Epidemiology, 2013, 24: 54-61

13 Wong G W K, Hui D S C, Chan C C, et al. Prevalence of respiratory and atopic disorders in Chinese schoolchildren. Clin Exp Allergy, 2001, 31: 1225-1231

14 Stewart A W, Mitchell E A, Pearce N, et al. The relationship of per capita gross national product to the prevalence of symptoms of asthma and other atopic diseases in children (ISAAC). Int J Epidemiol, 2001, 30: 173-179

15 Leech J A, Nelson W C, Burnett R T, et al. It's about time: A comparison of Canadian and American time-activity patterns. J Exposure Anal Environ Epidemiol, 2002, 12: 427-432

16 Brasche S, Bischof W. Daily time spent indoors in German homesBaseline data for the assessment of indoor exposure of German occupants. Int J Hyg Environ Health, 2005, 208: 247-253

17 Wargocki P, Sundell J, Bischof W, et al. Ventilation and health in non-industrial indoor environments: Report from a European Multidisciplinary Scientific Consensus Meeting (EUROVEN). Indoor Air, 2002, 12: 113-128

18 Sundell J. On the history of indoor air quality and health. Indoor Air, 2004, 14: 51-58

19 Bornehag C G, Sundell J, Sigsgaard T. Dampness in buildings and health $(\mathrm{DBH})$ : Report from an ongoing epidemiological investigation on the association between indoor environmental factors and health effects among children in Sweden. Indoor Air, 2004, 14: 59-66

20 Sundell J, Wickman M, Pershagen G, et al. Ventilation in homes infested by house-dust mites. Allergy, 1995, 50: 106-112

21 Sundell J, Levin H, Nazaroff W W, et al. Ventilation rates and health: Multidisciplinary review of the scientific literature. Indoor Air, 2011, 21: 191-204

22 Sun Y X, Sundell J. Life style and home environment are associated with racial disparities of asthma and allergy in Northeast Texas children. Sci Total Environ, 2011, 409: 4229-4234
23 Bornehag C G, Sundell J, Hagerhed-Engman L, et al. Association between ventilation rates in 390 Swedish homes and allergic symptoms in children. Indoor Air, 2005, 15: 275-280

24 Bornehag C G, Sundell J, Weschler C J, et al. The association between asthma and allergic symptoms in children and phthalates in house dust: A nested case-control study. Environ Health Perspect, 2004, 112: 1393-1397

25 Choi H, Schmidbauer N, Sundell J, et al. Common household chemicals and the allergy risks in pre-school age children. PLoS One, 2010, 5: e13423

26 Weiland S K, Bjorksten B, Brunekreef B, et al. Phase II of the international study of asthma and allergies in childhood (ISAAC II): rationale and methods. Eur Respir J, 2004, 24: 406-412

27 Ait-Khaled N, Pearce N, Anderson H R, et al. Global map of the prevalence of symptoms of rhinoconjunctivitis in children: The International Study of Asthma and Allergies in Childhood (ISAAC) Phase Three. Allergy, 2009, 64: 123-148

28 Andersson K, Bakke J V, Bjorseth O, et al. TVOC and health in nonindustrial indoor environments-Report from a Nordic scientific consensus meeting at Langholmen in Stockholm, 1996. Indoor Air, 1997, 7: 78-91

29 Ahlbom A, Backman A, Bakke J, et al. "NORDPET"-Pets indoors -A risk factor for or protection against sensitisation/allergy. Indoor Air, 1998, 8: 219-235

30 Bornehag C G, Blomquist G, Gyntelberg F, et al. Dampness in buildings and health. Indoor Air, 2001, 11: 72-86

31 Bornehag C G, Sundell J, Bonini S, et al. Dampness in buildings as a risk factor for health effects, EUROEXPO: A multidisciplinary review of the literature (1998-2000) on dampness and mite exposure in buildings and health effects. Indoor Air, 2004, 14: 243-257

32 Schneider T, Sundell J, Bischof W, et al. 'EUROPART'. Airborne particles in the indoor environment. A European interdisciplinary review of scientific evidence on associations between exposure to particles in buildings and health effects. Indoor Air, 2003, 13: 38-48

33 van Odijk J, Kull I, Borres M P, et al. Breastfeeding and allergic disease: a multidisciplinary review of the literature (1966-2001) on the mode of early feeding in infancy and its impact on later atopic manifestations. Allergy, 2003, 58: 833-843

34 Tham K W, Zuraimi M S, Koh D, et al. Associations between home dampness and presence of molds with asthma and allergic symptoms among young children in the tropics. Pediatr Allergy Immunol, 2007, 18: $418-424$

35 Naydenov K, Melikov A, Markov D, et al. A comparison between occupants' and inspectors' reports on home dampness and their association with the health of children: The ALLHOME study. Build Environ, 2008, 43: 1840-1849

36 Hsu N Y, Lee C C, Wang J Y, et al. Predicted risk of childhood allergy, asthma, and reported symptoms using measured phthalate exposure in dust and urine. Indoor Air, 2012, 22: 186-199

37 Clausen G, Høst A, Toftum J, et al. Children's health and its association with indoor environments in Danish homes and daycare centres-Methods. Indoor Air, 2012, 22: 467-475

38 Choi J, Choi Y, Chun C, et al. An epidemiological investigation on housing characteristics and asthma and allergy among children in Seoul, Korea. In: The 12th International Conference on Indoor Air Quality and Climate, June 5-10, 2011, A647-3, Austin, Texas, 2011

39 Ronchetti R, Villa M P, Barreto M, et al. Is the increase in childhood asthma coming to an end? Findings from three surveys of schoolchildren in Rome, Italy. Eur Respir J, 2001, 17: 881-886

40 Braun-Fahrlander C, Gassner M, Grize L, et al. No further increase in asthma, hay fever and atopic sensitisation in adolescents living in Switzerland. Eur Respir J, 2004, 23: 407-413

41 National Cooperation Group on Childhood Asthma of China. Comparative analysis of the state of asthma prevalence in children from two nation-wide surveys in 1990 and 2000 (in Chinese). Chin J Tubercul Respira Dise, 2004, 27: 112-116

42 Chen Y Z, Zhao T B, Ding Y. A questionnaire based survey on prevalences of asthma, allergic rhinitis and eczema in five Chinese cities (ISAAC study) (in Chinese). Chin J Pediatr, 1998, 36: 352-355 
43 Lau Y L, Karlberg J. Prevalence and risk factors of childhood asthma, rhinitis and eczema in Hong Kong. J Paediatr Child Health, 1998, 34 : 47-52

44 Zhao T B, Wang H J, Chen Y Z, et al. Prevalence of childhood asthma, allergic rhinitis and eczema in Urumqi and Beijing. J Paediatr Child Health, 2000, 36: 128-133

45 Wong G W K, Leung T F, Ma Y, et al. Symptoms of asthma and atopic disorders in preschool children: Prevalence and risk factors. Clin Exp Allergy, 2007, 37: 174-179

46 Zhao J, Bai J, Shen K, et al. Self-reported prevalence of childhood allergic diseases in three cities of China: A multicenter study. BMC Public Health, 2010, 10: 551

47 Li F, Zhou Y, Li S, et al. Prevalence and risk factors of childhood allergic diseases in eight metropolitan cities in China: A multicenter study. BMC Public Health, 2011, 11: 437

48 Zhao J, Bai J, Shen K L, et al. Questionnaire-based survey of allergic diseases among children aged 0-14 years in the downtown of Beijing, Chongqing and Guangzhou (in Chinese). Chin J Pediatr, 2011, 49: 740-744

49 Kong W, Chen J, Wang Y, et al. A population-based 5-year follow-up of allergic rhinitis in Chinese children. Am J Rhinol Allergy, 2012, 26: 315-320

$50 \mathrm{Xu} \mathrm{F}$, Yan S, Li F, et al. Prevalence of childhood atopic dermatitis: An urban and rural community-based study in Shanghai, China. PLoS One, 2012, 7: e36174

51 Yangzong Y, Shi Z, Nafstad P, et al. The prevalence of childhood asthma in China: A systematic review. BMC Public Health, 2012, 12: 860

52 Dong G H, Ma Y N, Ding H L, et al. Housing characteristics, home environmental factors and respiratory health in 3945 pre-school children in China. Int J Environ Health Res, 2008, 18: 267-282

53 Dong G H, Ma Y N, Ding H L, et al. Pets keeping in home, parental atopy, asthma, and asthma-related symptoms in 12,910 elementary school children from northeast China. Indoor Air, 2009, 19: 166-173

54 Physical Geography in China Editorial Board of Chinese Academy of Sciences. Physical Geography in China: Climatology. Beijing: Science Press, 1985

55 GB 50176. Thermal design code for civil building. 1993

56 Asher M, Keil U, Anderson H, et al. International Study of Asthma and Allergies in Childhood (ISAAC): Rationale and methods. Eur Respir J, 1995, 8: 483-491

57 Oppenheim A N. Questionnaire Design, Interviewing and Attitude Measurement. London: Continuum International Publishing Group, 1992

58 Zhao Z H, Zhang X, Liu R R, et al. Prenatal and early life home environment exposure in relation to preschool children's asthma, allergic rhinitis and eczema in Taiyuan, China. Chin Sci Bull, 2013, 58: 4245-4251

59 Wang $\mathrm{T} \mathrm{T}$, Zhao Z H, Yao $\mathrm{H}$, et al. Housing characteristics and indoor environment in relation to children's asthma, allergic diseases and pneumonia in Urumqi, China. Chin Sci Bull, 2013, 58: 42374244

60 Zhang M, Wu Y, Yuan Y, et al. Effects of home environment and lifestyles on prevalence of atopic eczema among children in Wuhan area of China. Chin Sci Bull, 2013, 58: 4217-4222

61 Zhang M, Zhou E S, Ye X, et al. Indoor environmental quality and the prevalence of childhood asthma and rhinitis in Wuhan area of China. Chin Sci Bull, 2013, 58: 4223-4229

62 Huang C, Hu Y, Liu W, et al. Pet-keeping and its impact on asthma and allergies among preschool children in Shanghai, China. Chin Sci Bull, 2013, 58: 4203-4210

63 Liu W, Huang C, Hu Y, et al. Associations between indoor environmental smoke and respiratory symptoms among preschool children in Shanghai, China. Chin Sci Bull, 2013, 58: 4211-4216

$64 \mathrm{Lu} \mathrm{C}$, Deng Q H, Ou C Y, et al. Effects of ambient air pollution on allergic rhinitis among preschool children in Changsha, China. Chin Sci Bull, 2013, 58: 4252-4258

65 Zheng X H, Qiang $\mathrm{H}$, Zhao Y L, et al. Home risk factors for childhood pneumonia in Nanjing, China. Chin Sci Bull, 2013, 58: 4230-4236

66 Wang H, Li B Z, Yang Q, et al. Dampness in dwellings and its associations with asthma and allergies among children in Chongqing: A cross-sectional study. Chin Sci Bull, 2013, 58: 4259-4266

67 Wang J, Li B Z, Yang Q, et al. Sick building syndrome among parents of preschool children in relation to home environment in Chongqing, China. Chin Sci Bull, 2013, 58: 4267-4276

68 Qu F, Weschler L B, Sundell J, et al. Increasing prevalence of asthma and allergy in Beijing pre-school children: Is exclusive breastfeeding for more than 6 months protective? Chin Sci Bull, 2013, 58: 4190-4202

69 Chan H H, Pei A, Van Krevel C, et al. Validation of the Chinese translated version of ISAAC core questions for atopic eczema. Clin Exp Allergy, 2001, 31: 903-907

70 Sun Y X, Sundell J, Zhang Y F. Validity of building characteristics and dorm dampness obtained in a self-administrated questionnaire. Sci Total Environ, 2007, 387: 276-282

71 Engman L H, Bornehag C G, Sundell J. How valid are parents' questionnaire responses regarding building characteristics, mouldy odour, and signs of moisture problems in Swedish homes? Scand J Public Health, 2007, 35: 125-132

72 Smith K R, Samet J M, Romieu I, et al. Indoor air pollution in developing countries and acute lower respiratory infections in children. Thorax, 2000, 55: 518-532

Open Access This article is distributed under the terms of the Creative Commons Attribution License which permits any use, distribution, and reproduction in any medium, provided the original author(s) and source are credited.

\section{Supporting Information}

Table S1 Questionnaire used in CCHH Phase I

Table S2 Comparison between short questionnaires and Phase I questionnaires in Chongqing

Table S3 Summary of general characteristics of the study populations, children 1-8 years old (\%)

Table S4 Summary of building characteristics in the investigated regions, children 1-8 years old (\%)

Table S5 Dampness and odor indices in homes in the investigated regions, children 1-8 years old (\%)

The supporting information is available online at csb.scichina.com and www.springerlink.com. The supporting materials are published as submitted, without typesetting or editing. The responsibility for scientific accuracy and content remains entirely with the authors. 